\title{
Evaluation and Injection Parameter Optimization for Polymer Flooding with Different Kinds of Profile Control Agents
}

\author{
Yikun Liu, ${ }^{1}$ Qingjun Deng, ${ }^{1,2}$ Gang Chen, ${ }^{2}$ Shuang Liang, ${ }^{1}$ and Lingyun Chen ${ }^{1}$ \\ ${ }^{1}$ Northeast Petroleum University, Daqing, Heilongjiang 163318, China \\ ${ }^{2}$ Daqing Oilfield Limited Company, Daqing, Heilongjiang 163000, China \\ Correspondence should be addressed to Gang Chen; 43973502@qq.com
}

Received 5 April 2013; Revised 26 June 2013; Accepted 1 August 2013

Academic Editor: Baojun Bai

Copyright (c) 2013 Yikun Liu et al. This is an open access article distributed under the Creative Commons Attribution License, which permits unrestricted use, distribution, and reproduction in any medium, provided the original work is properly cited.

\begin{abstract}
Injecting profile control agent (PCA) into deep reservoir can decrease the inefficient circulation of injected water effectively, which is critical to improve polymer flooding in heterogeneous reservoir. Polymer flooding contrast experiments were carried out with three PCAs, respectively; the influence of different injection times on recovery is analyzed, and the best injection rate of PCA is determined. The result shows that the effect of compound ion PCA, anionic delay-action cross-linking PCA, and luminum citrate cross-linking PCA gets worse in turn. The effect of injecting PCA before polymer flooding is better than that of injecting it during and after the procedure. As the PCA rate increases, the recovery increment raises, but the increasing ranges decrease. The best rate of PCA is $0.10 \mathrm{PV}$, considering technical and economic effects.
\end{abstract}

\section{Introduction}

To reduce the inefficient circulation of injected water in the formation, reduce production cost, and improve oilfield development, the effect of profile control on improving polymer flooding development has been explored since 1996 when polymer flooding began to be applied on largescale $[1,2]$. But the research on contrast, application condition, and the best injection time and injection rate optimization for different PCAs is still in an exploratory stage [3-5].

From research before, we can know some information about these PCAs. Compound ion PCA [6] is a kind of compound ion cross-linker system made up with compound ion polymer, cross-linker, and assistant with certain proportion. It performs well in injection and gelation and has certain shear resistance, thus it can have an effect in profile control. Anionic delay-action cross-linking PCA uses anionic polymer as cross-linker. It has notable elasticity, large absorption, high residual resistance factor, and obvious profile control effect. Aluminum citrate cross-linking PCA [7] does not contain sulfate radical, nitrate radical, and metallic iron, whose mass fraction for aluminum ions is more than $4.17 \%$. In some ranges of polymer concentration, aluminum citrate cross-linking system (HPAM) can form polymer jelly with high strength.

\section{Experiment}

2.1. Experimental Conditions. Quartz sand epoxy cementation artificial cores and three cores in parallel connection with positive rhythm are used, whose water phase permeability is $0.2 \mu \mathrm{m}^{2}, 0.5 \mu \mathrm{m}^{2}$, and $0.8 \mu \mathrm{m}^{2}$ and core size is $30 \mathrm{~cm} \times 4.5 \mathrm{~cm}$ $\times 4.5 \mathrm{~cm}$. The viscosity of oil in experiment is $10 \mathrm{mPa} \cdot \mathrm{s}\left(45^{\circ} \mathrm{C}\right)$. The water is drained after filtration. The polymer is APAM, whose relative molecular mass is 13 million. The PCAs are, respectively, compound ion PCA, anionic delay-action crosslinking PCA, and aluminum citrate cross-linking PCA.

\subsection{Experimental Program}

2.2.1. Basic Flooding Experiment. (a) Saturated with oil, water flooding until $98 \%$ water cut $+0.69 \mathrm{PV} 1500 \mathrm{mg} / \mathrm{L}$ polymer with medium molecular weight + subsequent water flooding until $98 \%$ water cut; (b) saturated with oil, water flooding until $98 \%$ water cut $+0.74 \mathrm{PV} 1500 \mathrm{mg} / \mathrm{L}$ polymer with medium molecular weight + subsequent water flooding until 
TABLE 1: Result of basic polymer flooding experiment.

\begin{tabular}{lccccc}
\hline Injected slug & $\begin{array}{c}\text { Water phase permeability } \\
\left(10^{-3} \mu \mathrm{m}^{2}\right)\end{array}$ & Porosity (\%) & Oil saturation (\%) & $\begin{array}{c}\text { Water flooding } \\
\text { recovery (\%) }\end{array}$ & $\begin{array}{c}\text { Polymer flooding } \\
\text { EOR (\%) }\end{array}$ \\
\hline $0.69 \mathrm{PV}$ & 512 & 24.35 & 73.36 & 45.36 & 13.07 \\
$0.74 \mathrm{PV}$ & 516 & 24.50 & 73.44 & 45.02 & 13.81 \\
$0.84 \mathrm{PV}$ & 509 & 24.51 & 73.69 & 45.05 & 14.19 \\
\hline
\end{tabular}

98\% water cut; (c) saturated with oil, water flooding until $98 \%$ water cut $+0.84 \mathrm{PV} 1500 \mathrm{mg} / \mathrm{L}$ polymer with medium molecular weight + subsequent water flooding until $98 \%$ water cut.

2.2.2. Profile Control Experiment before Polymer Flooding. (a) Saturated with oil, water flooding until $98 \%$ water cut $+0.05 \mathrm{PV} \mathrm{PCA}+0.64 \mathrm{PV} 1500 \mathrm{mg} / \mathrm{L}$ polymer with medium molecular weight + subsequent water flooding until $98 \%$ water cut; (b) saturated with oil, water flooding until 98\% water cut + 0.10PV PCA + 0.64PV $1500 \mathrm{mg} / \mathrm{L}$ polymer with medium molecular weight + subsequent water flooding until 98\% water cut; (c) saturated with oil, water flooding until $98 \%$ water cut + 0.20PV PCA + 0.64PV $1500 \mathrm{mg} / \mathrm{L}$ polymer with medium molecular weight + subsequent water flooding until $98 \%$ water cut.

2.2.3. Profile Control Experiment in the Middle of Polymer Flooding. (a) Saturated with oil, water flooding until $98 \%$ water cut + 0.10PV $1500 \mathrm{mg} / \mathrm{L}$ polymer with medium molecular weight + 0.05PV PCA + 0.54PV $1500 \mathrm{mg} / \mathrm{L}$ polymer with medium molecular weight + subsequent water flooding until 98\% water cut; (b) saturated with oil, water flooding until $98 \%$ water cut + 0.10PV $1500 \mathrm{mg} / \mathrm{L}$ polymer with medium molecular weight + 0.10PV PCA + 0.54PV $1500 \mathrm{mg} / \mathrm{L}$ polymer with medium molecular weight + subsequent water flooding until 98\% water cut; (c) saturated with oil, water flooding until $98 \%$ water cut + 0.10PV $1500 \mathrm{mg} / \mathrm{L}$ polymer with medium molecular weight + 0.20PV PCA + 0.54PV $1500 \mathrm{mg} / \mathrm{L}$ polymer with medium molecular weight + subsequent water flooding until $98 \%$ water cut.

2.2.4. Profile Control Experiment After Polymer Flooding. (a) Saturated with oil, water flooding until $98 \%$ water cut + $0.64 \mathrm{PV} 1500 \mathrm{mg} / \mathrm{L}$ polymer with medium molecular weight $+0.05 \mathrm{PV}$ PCA + subsequent water flooding until $98 \%$ water cut; (b) saturated with oil, water flooding until 98\% water cut + 0.64PV $1500 \mathrm{mg} / \mathrm{L}$ polymer with medium molecular weight $+0.10 \mathrm{PV}$ PCA + subsequent water flooding until $98 \%$ water cut; (c) saturated with oil, water flooding until 98\% water cut $+0.64 \mathrm{PV} 1500 \mathrm{mg} / \mathrm{L}$ polymer with medium molecular weight $+0.20 \mathrm{PV}$ PCA + subsequent water flooding until $98 \%$ water cut.

\section{Results Analysis}

3.1. Effect of Basic Polymer Flooding. From Table 1, we can see that the extent of polymer flooding EOR increases with the increase of polymer quantity.

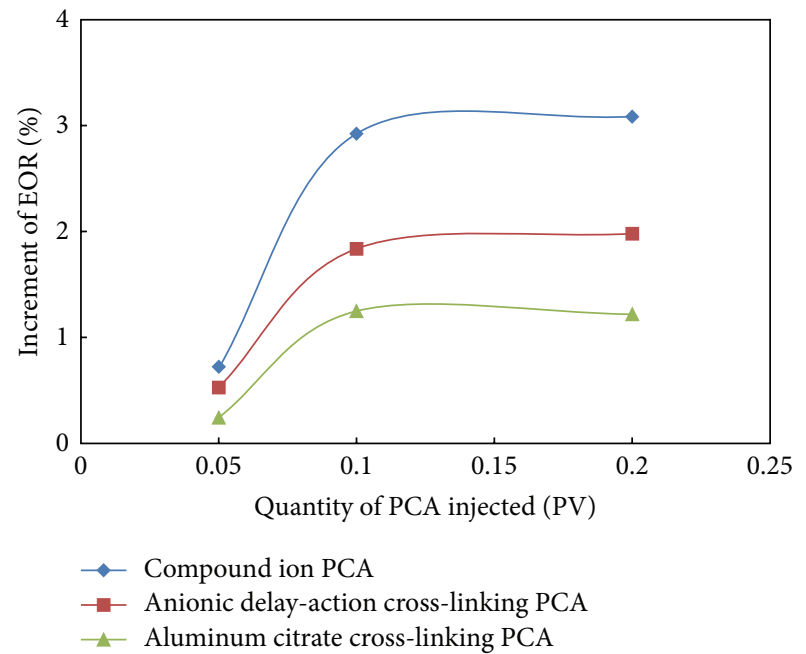

FIgURE 1: The relation between injected PV of PCA and recovery increment before polymer flooding.

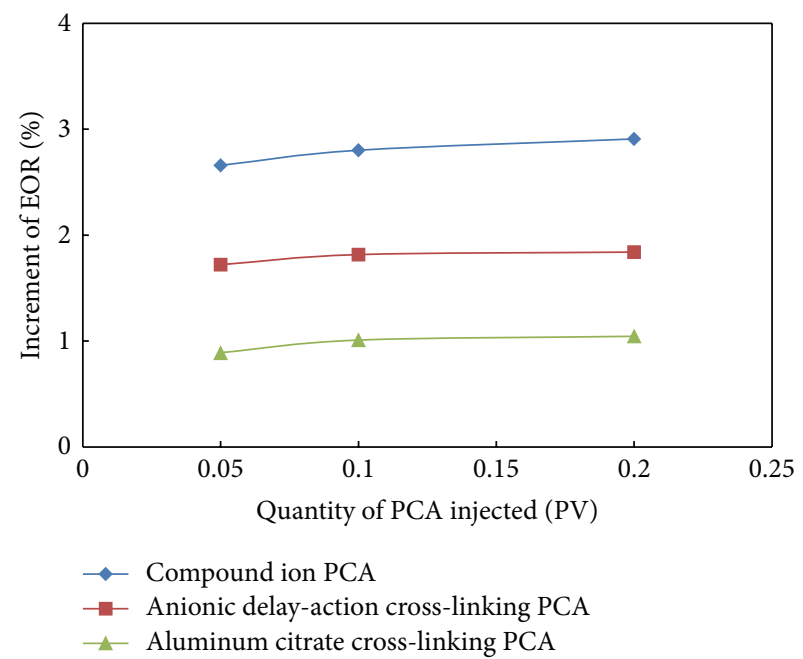

FIgURE 2: The relation between injected PV of PCA and recovery increment during polymer flooding.

The result of polymer flooding experiment will be the standard to contrast between displacement effects with different PCAs, different injection times, and different injection rates.

3.2. Result of Polymer Flooding with PCA. From Figures 1,2 , and 3, we can see that compound ion PCA, anionic delay-action cross-linking PCA, and aluminum citrate crosslinking PCA get worse in sequence and the effect of injecting 
Table 2: Prediction on output increment and economic benefit analysis for different PCA flooding.

\begin{tabular}{|c|c|c|c|c|c|c|c|}
\hline PCA types & Injection time & $\begin{array}{l}\text { Injection } \\
\text { rate }(\mathrm{PV})\end{array}$ & EOR (\%) & $\begin{array}{l}\text { Output increment } \\
\text { prediction }(\mathrm{cm})^{3}\end{array}$ & $\begin{array}{c}\text { Output } \\
\left(\times 10^{6} \mathrm{RMB}\right)\end{array}$ & $\begin{array}{c}\text { Input } \\
\left(\times 10^{6} \mathrm{RMB}\right) \\
\end{array}$ & $\begin{array}{c}\text { Input/output } \\
\text { ratio }\end{array}$ \\
\hline \multirow{7}{*}{ Compound ion PCA } & \multirow{3}{*}{ Before } & 0.05 & 0.67 & 0.49 & 759.5 & 320.35 & $1: 2.37$ \\
\hline & & 0.10 & 2.91 & 2.14 & 3317 & 640.7 & $1: 5.18$ \\
\hline & & 0.20 & 3.09 & 2.27 & 3518.5 & 1281.4 & $1: 2.75$ \\
\hline & Middle & 0.10 & 2.87 & 2.11 & 3270.5 & 640.7 & $1: 5.10$ \\
\hline & \multirow{3}{*}{ After } & 0.05 & 0.46 & 0.34 & 527 & 320.35 & $1: 1.65$ \\
\hline & & 0.10 & 2.03 & 1.49 & 2309.5 & 640.7 & $1: 3.60$ \\
\hline & & 0.20 & 2.58 & 1.90 & 2945 & 1281.4 & $1: 2.30$ \\
\hline \multirow{7}{*}{$\begin{array}{l}\text { Anionic delay-action } \\
\text { cross-linking PCA }\end{array}$} & \multirow{3}{*}{ Before } & 0.05 & 0.49 & 0.36 & 558 & 255.35 & $1: 2.19$ \\
\hline & & 0.10 & 1.83 & 1.35 & 2092.5 & 510.7 & $1: 4.10$ \\
\hline & & 0.20 & 1.95 & 1.43 & 2216.5 & 1021.4 & $1: 2.17$ \\
\hline & Middle & 0.10 & 1.62 & 1.19 & 1844.5 & 510.7 & $1: 3.61$ \\
\hline & \multirow{3}{*}{ After } & 0.05 & 0.18 & 0.13 & 201.5 & 255.35 & $1: 0.79$ \\
\hline & & 0.10 & 1.76 & 1.29 & 1999.5 & 510.7 & $1: 3.92$ \\
\hline & & 0.20 & 1.70 & 1.25 & 1937.5 & 1021.4 & $1: 1.90$ \\
\hline \multirow{7}{*}{$\begin{array}{l}\text { Aluminum citrate cross-linking } \\
\text { PCA }\end{array}$} & \multirow{3}{*}{ Before } & 0.05 & 0.24 & 0.18 & 279 & 155.35 & $1: 1.80$ \\
\hline & & 0.10 & 1.24 & 0.91 & 1410.5 & 310.7 & $1: 4.54$ \\
\hline & & 0.20 & 1.26 & 0.93 & 1441.5 & 621.4 & $1: 2.32$ \\
\hline & \multirow[t]{2}{*}{ Middle } & 0.10 & 1.40 & 1.03 & 1596.5 & 310.7 & $1: 5.14$ \\
\hline & & 0.05 & 0.11 & 0.08 & 124 & 155.35 & $1: 0.80$ \\
\hline & \multirow[t]{2}{*}{ After } & 0.10 & 0.45 & 0.33 & 511.5 & 310.7 & $1: 1.65$ \\
\hline & & 0.20 & 0.90 & 0.66 & 1023 & 621.4 & $1: 1.65$ \\
\hline
\end{tabular}

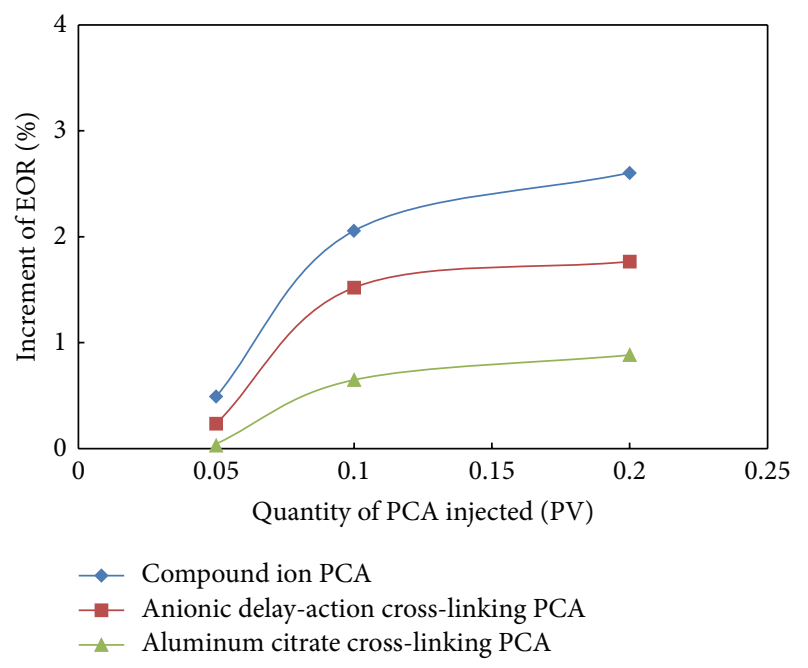

FIgURE 3: The relation between injected PV of PCA and recovery increment after polymer flooding.

PCA before polymer flooding is better than that of injecting it during and after the procedure. As PCA injection increases, recovery increment increases as well, but the increment gets smaller when PCA quantity is greater than $0.1 \mathrm{PV}$.

3.3. Economic Benefit Analysis. From Table 2, we can see that when crude oil output price is 2,000 Yuan/ton and the cost is
450 Yuan/ton, the best injection rate of PCA is $0.10 \mathrm{PV}$, when the input/output ratio reaches a maximum.

\section{Conclusions}

The effect of compound ion PCA, anionic delay-action crosslinking PCA, and aluminum citrate cross-linking PCA gets worse in sequence, and the effect of injecting PCA before polymer flooding is better than that of injecting it during and after the procedure. The best injection rate of PCA is $0.10 \mathrm{PV}$, when input/output ratio reaches a maximum. The increment of EOR gets smaller when PCA quantity is bigger than 0.10PV. Thus, it is important to further analyze the effect of different PCAs, and the best injection time and quantity upon the establishment and application of PCA injecting scheme in situation.

\section{Acknowledgments}

This work is financially supported by National Natural Science Foundation of China (51074035) and Major Projects of National Science and Technology of China (2011ZX05010002-05 and 2011ZX05052-12).

\section{References}

[1] Z. Sun, Y. Zheng, M. Li, M. Lin, and Z. Wu, "Study on mechanism of plugging porous media of linked polymer solution," 
Polymeric Materials Science \& Engineering, vol. 21, no. 2, pp. 225-228, 2005.

[2] L. He, W. Xin, and L. Guo, "Enhanced oil recovery technology continually after polymer-flooding," in Proceedings of the SPE Enhanced Oil Recovery Conference (EORC '11), 144250, Kuala Lumpur, Malaysia, July 2011.

[3] Q. You, Y. Tang, and C. Dai, "Research on a new profile control agent: dispersed particle gel," in Proceedings of the SPE Enhanced Oil Recovery Conference (EORC '11), 143514, Kuala Lumpur, Malaysia, July 2011.

[4] M.-Y. Li, M.-Q. Lin, X.-Y. Zheng, and Z.-L. Wu, "Linked polymer solution as in-depth permeability control agent: laboratory study and field test," Oilfield Chemistry, vol. 17, no. 2, pp. 144-147, 2000.

[5] K. Wang, Y. Ding, Y. Yan et al., "Physical simulation of oil displacement effect by using ASP composite PCA," Northeast Petroleum University Press, vol. 29, no. 1, pp. 31-32, 2005.

[6] Z. Yue, "Aluminum citrate crosslinker preparation and research on its crosslinking system," Special Oil \& Gas Reservoirs, vol. 15, no. 1, 2008.

[7] B. Wu, "Laboratory research on water plugging and control for exploiting potentialities in injection and production wells," Oil Drilling \& Production Technology, vol. 34, no. 3, 2012. 

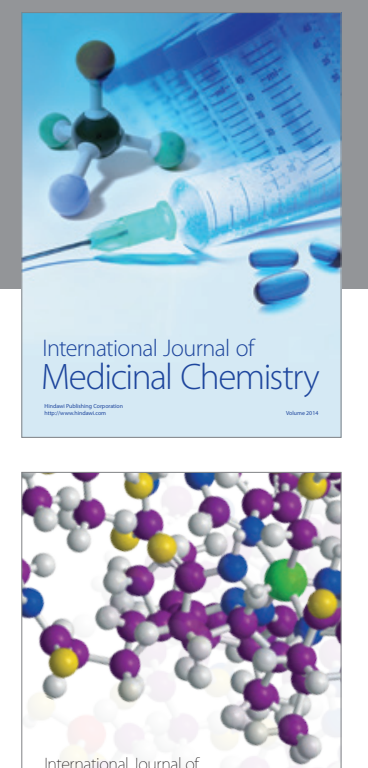

\section{Carbohydrate} Chemistry

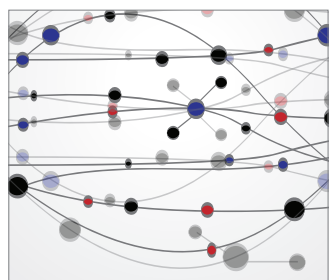

The Scientific World Journal
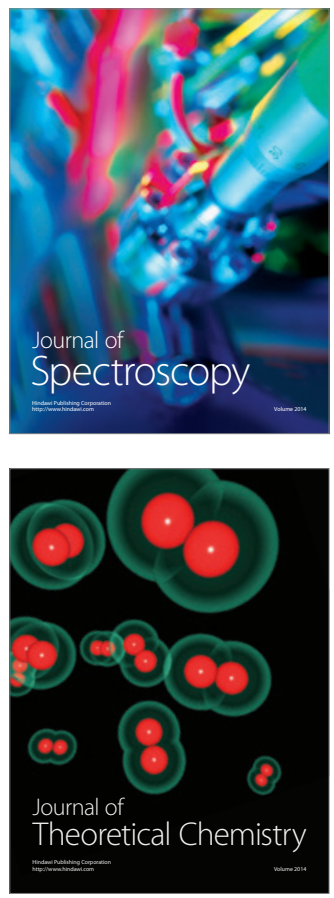
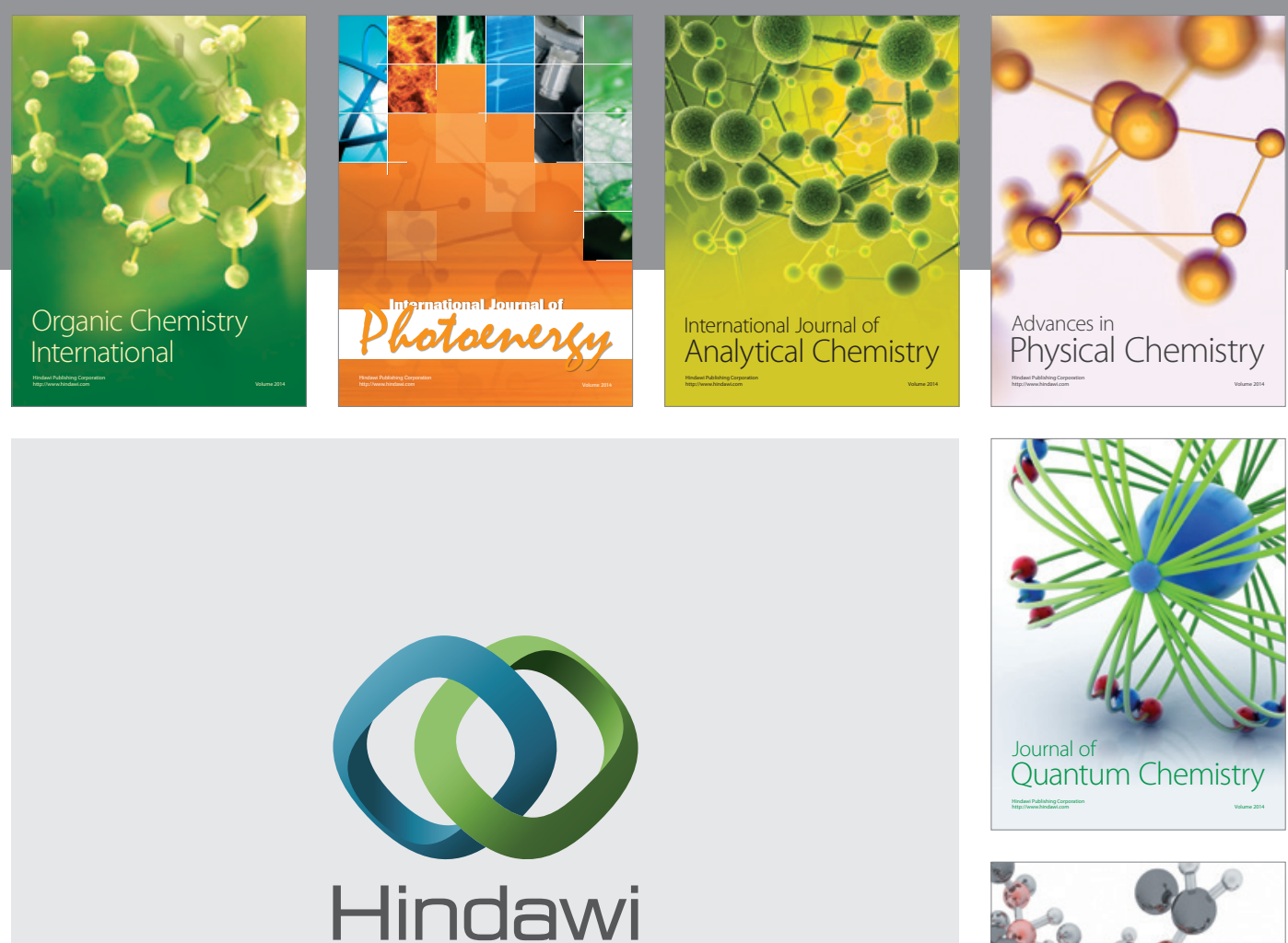

Submit your manuscripts at

http://www.hindawi.com

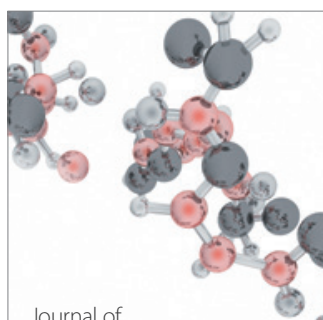

Analytical Methods

in Chemistry

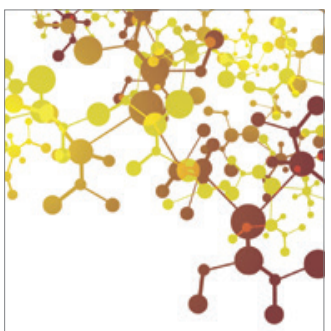

Journal of

Applied Chemistry

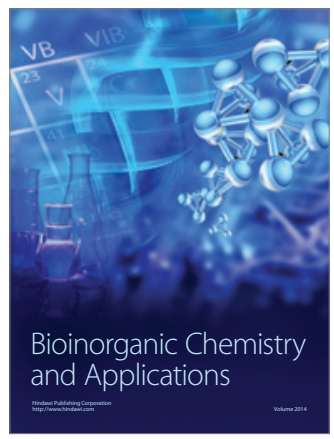

Inorganic Chemistry
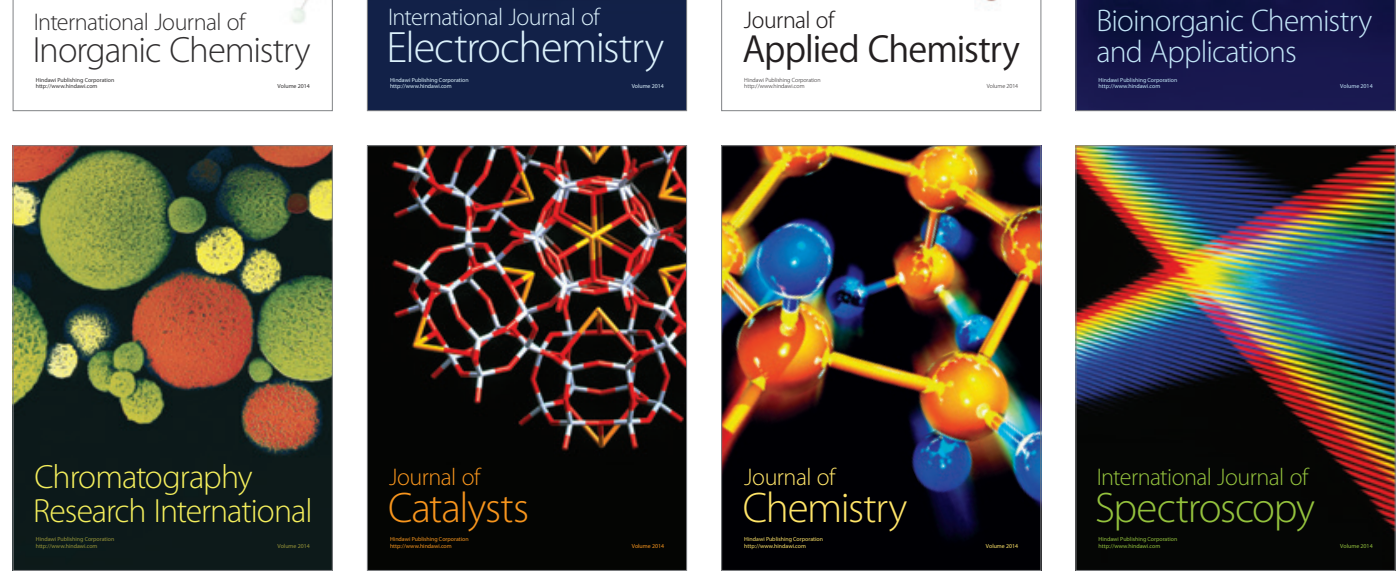